\title{
KALOTERMES MILLERI, A NEW SPECIES OF TERMITE FROM THE FLORIDA KEYS AND JAMAICA (ISOPTERA, KALOTERMITID $Æ)^{1}$
}

\author{
By Alfred E. Emerson \\ Hull Zoological Laboratory, University of Chicago
}

The number of undescribed species of termites to be found within the borders of the United States is probably quite small. During trips to Florida (1941) and to the southwestern states (1937, 1941) extensive collections of termites were made enabling me to make new associations of reproductive castes with soldiers in several instances, to gather sufficient population samples to indicate that several named forms are only variants and should not be classified as distinct species, and to extend and clarify the ranges of distribution of many species. After a more thorough study of these collections, I plan to publish a revision of the termites of the United States. As such a study may take several years to complete, it seems best to add the following species to the fauna without delay.

This new species of Kalotermes is the smallest member of the genus (s. str.) in the United States. The fact that it is found both in the Florida Keys and in Jamaica is not surprising as there are a number of Neotropical species of termites which reach the southern tip of Florida but do not extend north of the tropical area. In time it may be expected that this species will be found in Cuba and possibly other West Indian islands.

\section{Kalotermes milleri, new species}

Imago (figs. 1 and 2).

Head, pronotum and abdominal tergites dark shining brown; labrum yellow; sternites a little lighter than the tergites; femora, tibiae and tarsi light yellowish; costal margin of wing and radial veins brown, wing membrane hyaline.

${ }^{1}$ The present investigation was aided by a grant from the Dr. Wallace C. and Clara A. Abbott Memorial Fund of the University of Chicago. 
Head and pronotum with scattered bristles and hairs; each tergite and sternite with a few short hairs and long bristles on the posterior portion.

Head oval, the Y-suture not conspicuous. Eye fairly small (fig. 2), somewhat angular, about two-thirds of its long diameter from the lower margin. Ocellus in contact with the eye or close to the eye with only a thin brown line separating it from the ocular suture. Antennae with thirteen articles, the third equal to or slightly shorter than the second and about equal to or a little longer than the fourth.

Pronotum (fig. 1) about the width of the head, about fiveeighths as long in the middle as the width, with slightly rounded sides, front margin evenly concave and hind margin slightly emarginate. Forewing scale overlapping the base of the hindwing scale when at rest. In the forewing the subcostal vein joins the costal border close to the suture, $R_{1}$ absent, $R_{2+3}$ runs singly to the costal border a little beyond $S c, R_{4+5}$ with about six superior branches, $M$ weaker than the radius and running midway between the radius and cubitus, $C u$ running out near the tip of the wing with numerous inferior branches. Anal vein in the hindwing quite thick. Arolium present between the tarsal claws.

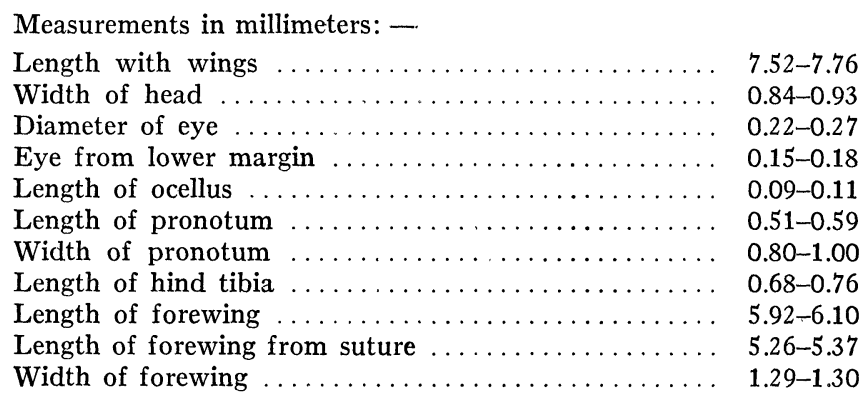

Paratype alates of $K$. bequaerti Snyder from Banos, Oriente, Cuba have longer wings, are yellow instead of dark brown, and have a distinctly larger eye.

Soldier (figs. 3, 4 and 5).

Head and body yellowish with the front of the head and mandibles a contrasting dark brown to black. 
Head, pronotum and tergites with a number of scattered bristles.

Head (fig. 3) elongate with somewhat curved or straight parallel sides; a thick prominent dark ridge above the base of the antenna; a whitish eye spot behind the base of the antenna. Postmentum ("gula") about half or less than half as wide in the middle portion as in the anterior region (fig. 5), sides rather evenly concave from the widest region to the posterior end. Mandibles (figs. 3 and 5) with bases slightly curved on the outside edge and tips curved inward; left mandible with three marginal teeth, the second and third with sinuate edges together making a symmetrical marginal outline; the right mandible with two prominent marginal teeth about equal in size. Antennae with ten to eleven articles, the third about twice the length of the second and darker than the outer articles.

Pronotum (fig. 3) proportionately long, sides fairly straight, front margin angularly emarginate and edges somewhat turned up to fit the back of the head and sometimes flared outward at the junction with the sides, hind margin evenly and convexly curved. Femora swollen and tibiae rather short and thick, less than half as wide as the femora. Tibiae with three terminal thick dark spines.

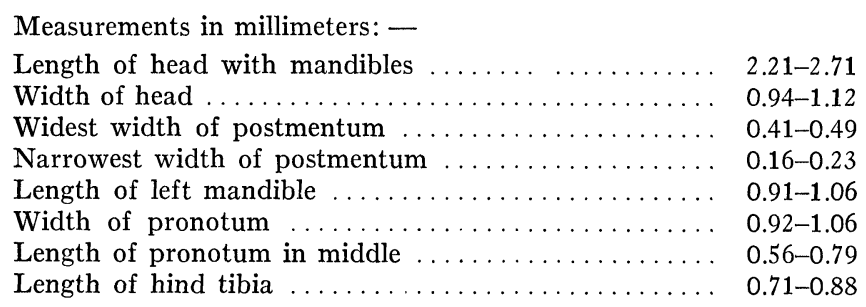

A single paratype soldier of $K$. bequaerti Snyder from Banos, Oriente, Cuba has proportionately wider pronotum and the tips of the mandibles are a little straighter. I am not sure that these characters will always show specific distinction in a large series.

The descriptions are based upon eight reproductives and about thirty-seven soldiers. Samples from eight colonies were collected on the Florida Keys by Dr. E. M. Miller of the University of Miami, Coral Gables, Florida, and by the author. I have recently received samples from three colonies collected in Jamaica by Dr. E. A. Chapin of the U. S. National Museum to 
whom I am indebted for these and other collections. I take pleasure in naming this species in honor of Dr. E. M. Miller who has collected extensively in Florida and who has recently published interesting studies on caste development in Prorhinotermes. Dr. Miller has a paper in press dealing with Florida termites. The collection records of $K$. milleri are as follows: -

Type locality: - Elliott Key, Florida: holotype queen, morphotype soldier, and paratype king and soldiers collected by E. M. Miller, 7.II.1942; paratype dealate and soldiers from four colonies collected by A. E. Emerson, 22.III.1941; paratype soldiers collected by E. M. Miller, 7.V.1938.

Other localities: - Key Largo, Florida: paratype soldiers from two colonies collected by E. M. Miller, 21.III.1931. Bluefields Bay, Jamaica: paratype alates and soldier collected by E. A. Chapin, 20.V.1941, Sta. 588, in old stump. Portland Ridge, Jamaica: paratype dealate and soldiers collected by E. A. Chapin, 3.V.1941, Sta. 539, dead standing tree; paratype soldier collected by E. A. Chapin, 3.V.1941, Sta. 537, dead tree.

The holotype queen, morphotype soldier and a series of paratypes are deposited in the collection of the American Museum of Natural History now in the author's possession. Paratypes will be deposited in the U. S. National Museum, Museum of Comparative Zoölogy and Field Museum of Natural History.

The general biology of the species as far as observed conforms with that of its congeners. It is found in dead hard wood in logs, stumps, standing dead trees and dead branches of living trees. The galleries are often comparatively small in conformity with the small diameter of the soldiers and nymphs. The eggs are laid singly in the galleries inhabited by the queen without any differentiated royal cell. Pellets of excrement are deposited in some of the galleries. It is to be expected that the species will ultimately be found in the hard wood of buildings within the area of its natural range.

Explanation of Plate III

Kalotermes milleri, new species

Fig. 1. Head and pronotum of imago from above.

FIG. 2. Head of imago from side.

FIg. 3. Head and pronotum of soldier from above.

Fig. 4. Head and pronotum of soldier from side.

Fig. 5. Head of soldier from below. 


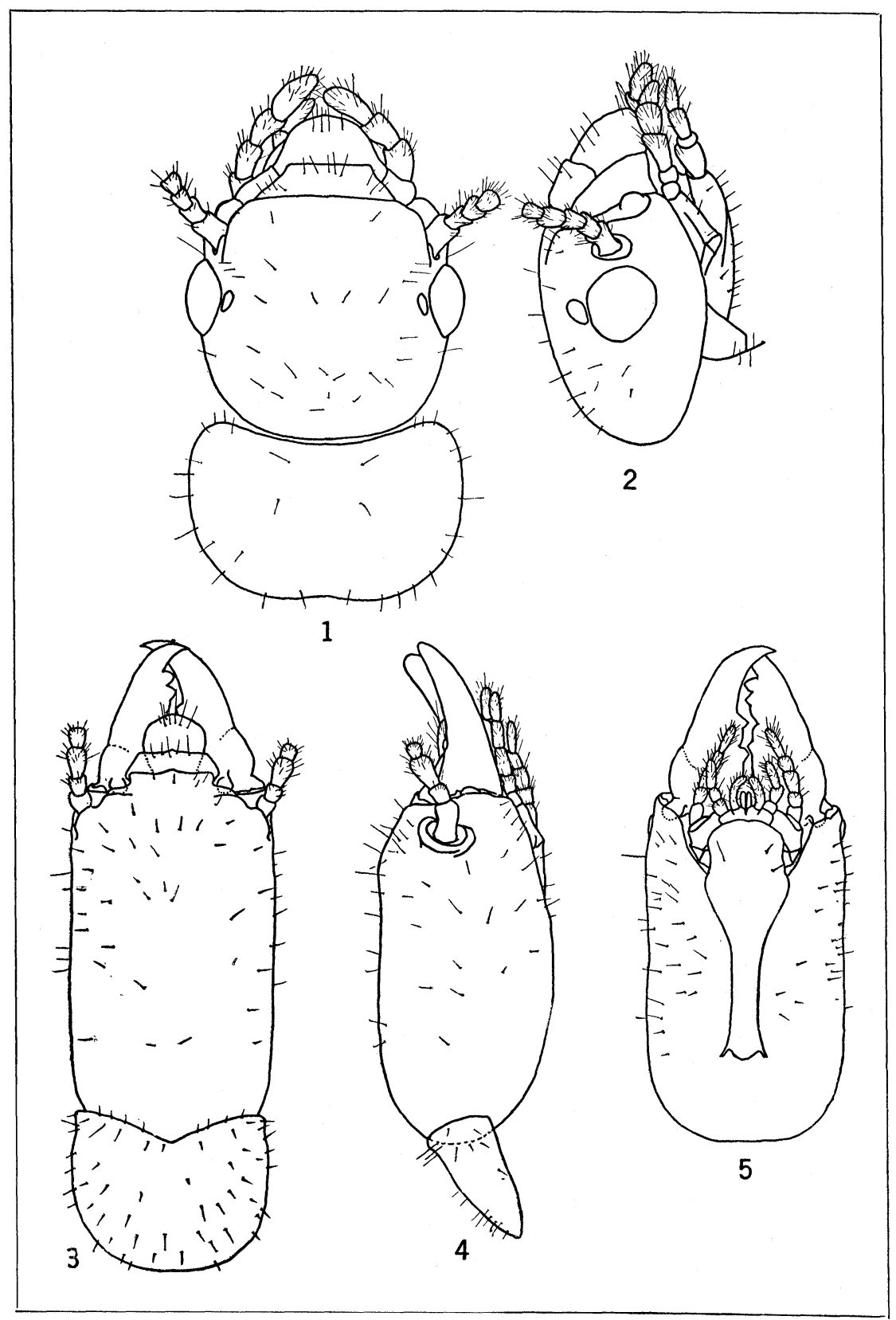



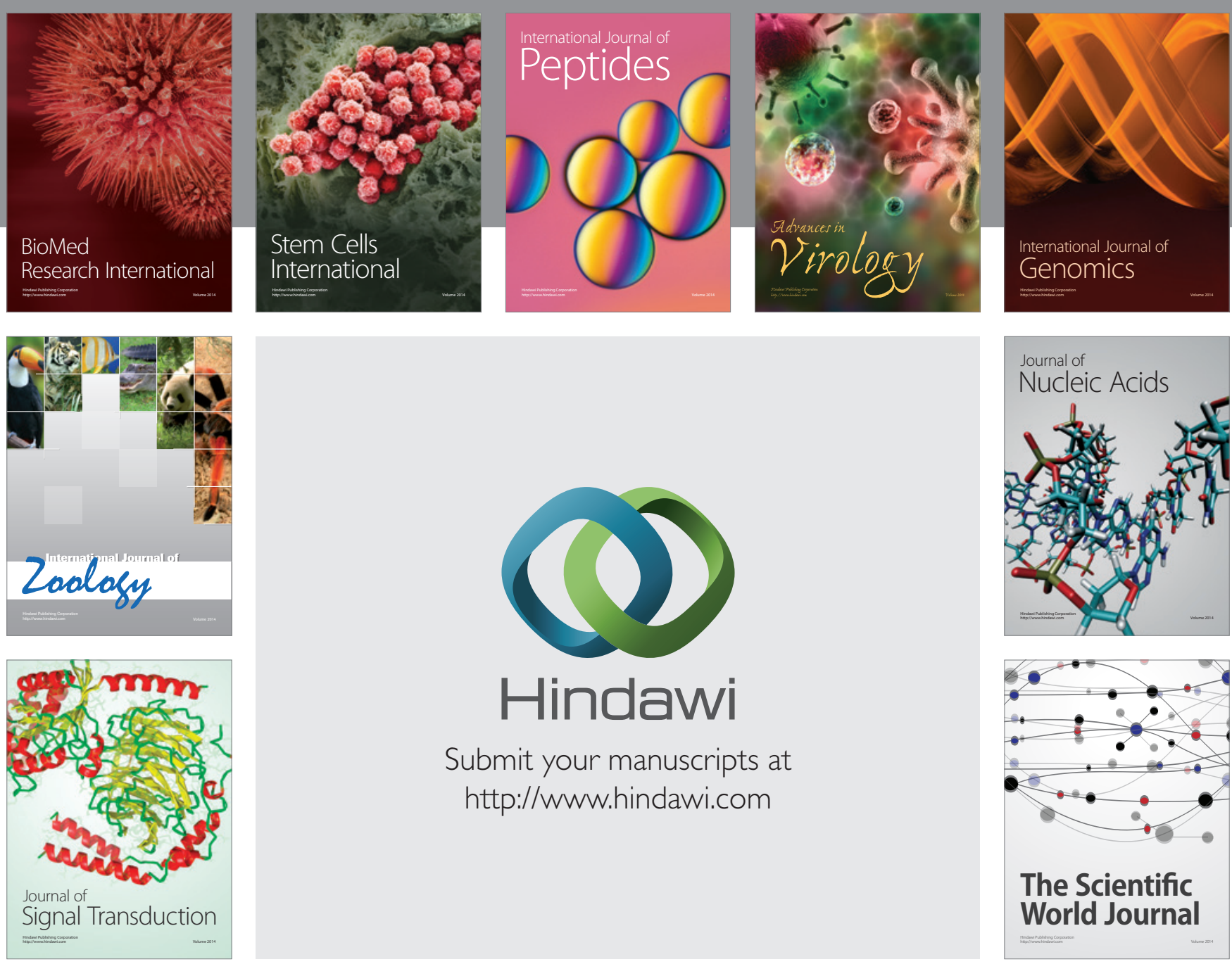

Submit your manuscripts at

http://www.hindawi.com
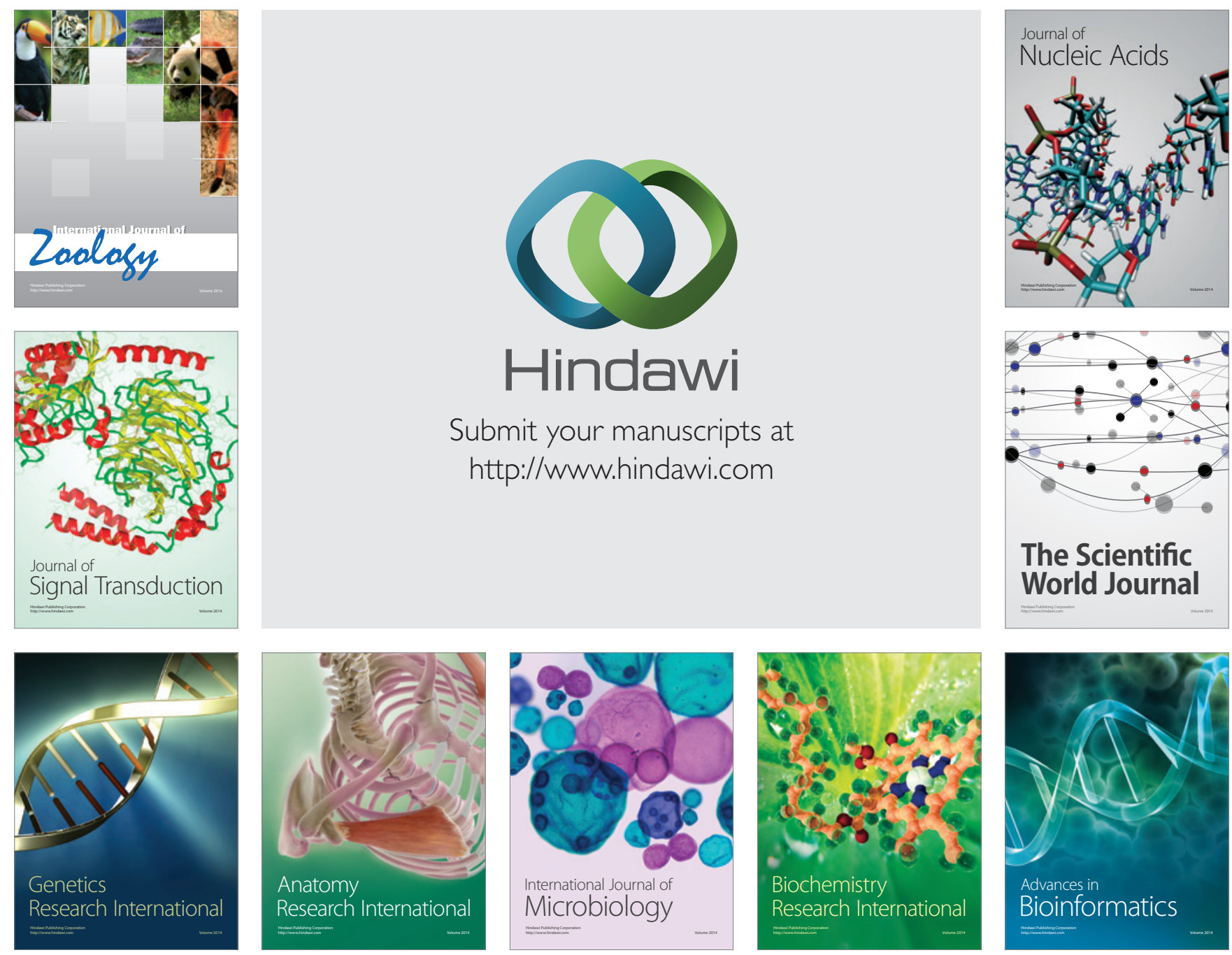

The Scientific World Journal
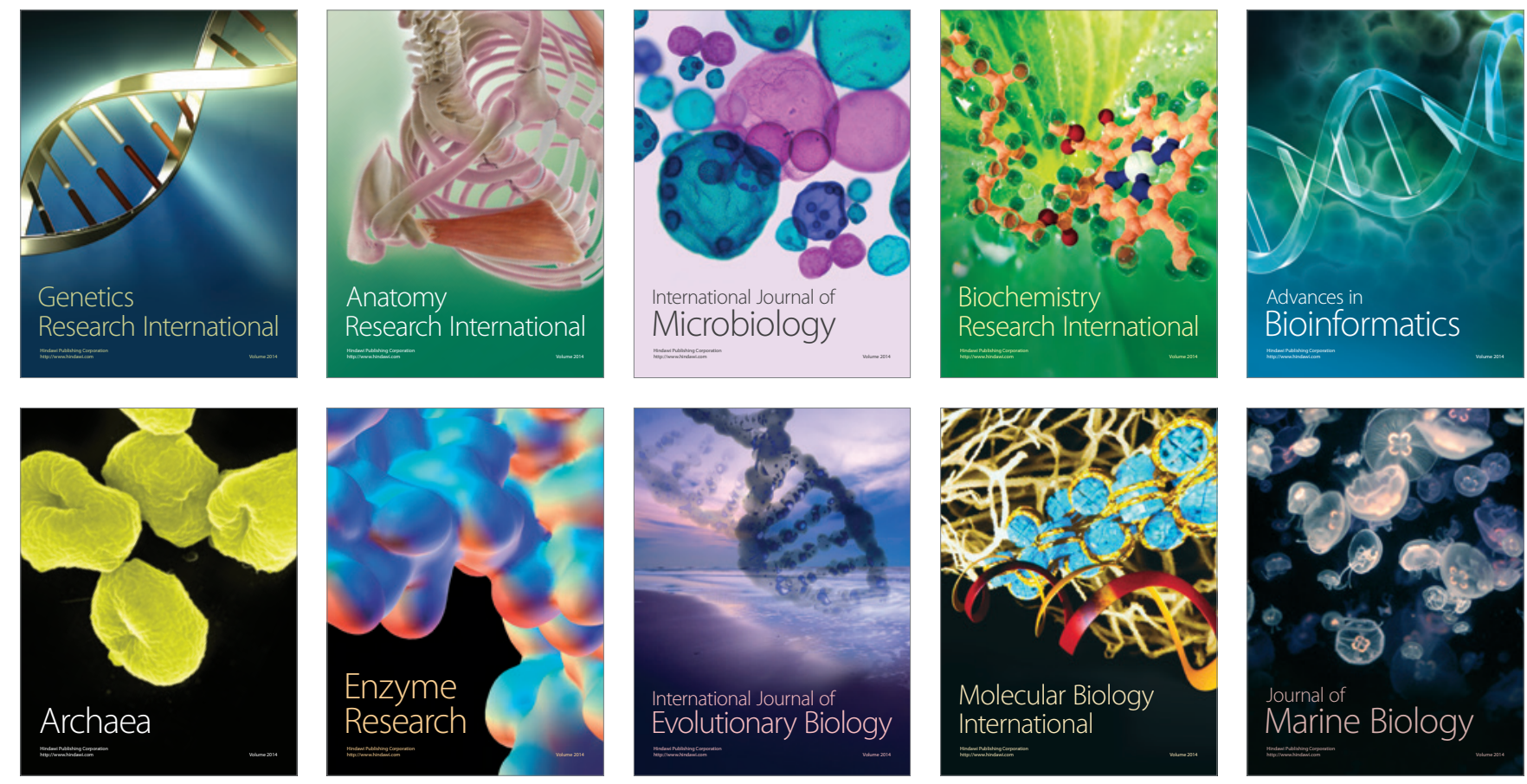